\title{
Wettability study of lead free solder paste and its effect towards multiple reflow
}

\author{
Siti Rabiatull Aisha Idris ${ }^{1 a}$, Siti Zuleikha ${ }^{1}$ and Zetty Akhtar Abd Malek ${ }^{1}$ \\ ${ }^{1}$ Faculty of Mechanical Engineering, Universiti Malaysia Pahang, 26600 Pekan, Pahang, Malaysia
}

\begin{abstract}
Nowadays, wafer bumping using solder paste has come into focus as it provides a low cost method. However, since the industries are moving towards lead-free electronic packaging, a new type of no-clean flux was produced specifically for lead-free solder paste. Therefore, this study is used to evaluate the wettability of two different types of no-clean flux onto copper substrate. Besides, its effect towards multiple reflow was also studied. Reflow soldering was conducted for both types of solder paste that contained different type of no-clean flux for up to double reflow. Two different reflow profile was used. The results showed that the Flux A exhibit better soldering performance after first and second reflow soldering. In addition, type of intermetallic compound (IMC) found after first reflow remain the same even after second reflow which was $\mathrm{Cu}-\mathrm{Sn}$ based. This is shows that Flux A manage to control the diffusion process which will finally leads to a better solder joint performance. Nevertheless, mechanical testing should be carried out in order to evaluate the solder joint strength.
\end{abstract}

\section{Introduction}

As the electronic industry is shifting towards using lead-free solders, solder paste has become popular choice since it can form reliable solder joint in printed circuit board (PCB) through reflow soldering [1-3]. Solder paste is a homogeneous mixture of flux and also highly-graded solder alloy in powder form particles and has a great effect on solder joint quality [1]. However, to give a reliable solder joint, the flux itself must have an excellent chemical activity to remove the oxide on the surface of the substrate as well as on the surface of the solder particles. With that, it manage to promote good spreading and finally giving reliable bonding with the substrate [2]. Other than that, it also must easily be activated thermally but at the same time must not easily decomposed. Last but not least, it should be able to form benign residues that can be easily removed by washing $[1,4,5]$.

Various lead-free solder alloys have been studied and used for electronics components and assemblies. Based on the results of many investigations, 96.5Sn$3.0 \mathrm{Ag}-0.5 \mathrm{Cu}$ solder alloy had been selected since it possesses properties which could replace lead solder [68]. Though, this type of solder alloy has some disadvantages such as higher melting point $\left(216-218^{\circ} \mathrm{C}\right)$ and poor wettability as compared to tin-lead solder. Thus, the best alternative way is yet to be achieved since a lot of studies for lead-free solders are still undergoing the researches.
Apart from that, one of the crucial factors in Sncontained solder joints reliability is the formation of a $\mathrm{Cu}-\mathrm{Sn}$ intermetallic compound (IMC) between the solder alloy and copper substrate. The formation of this IMC starts with diffusion of Sn toward copper substrate after reflow soldering. Then a layer of $\mathrm{Cu}$-Sn IMC starts to form which normally known as $\mathrm{Cu}_{6} \mathrm{Sn}_{5}$. This IMC will continuously grow when exposed to subsequent reflow. In some cases, $\mathrm{Cu}_{3} \mathrm{Sn}$ was found between $\mathrm{Cu}_{6} \mathrm{Sn}_{5}$ and copper substrate. In general, IMC served as a bonding material for the solder joint, but it also one of the main factors that affect the reliability of the solder joint due to its brittle nature and thermal mismatch with the solder and printed circuit board (PCB). Therefore, excessive IMC formed at the solder/ $\mathrm{Cu}$ interface of the solder joint will finally weaken the joint strength and finally may cause failure [9-11].

In this study, wettability of the $\mathrm{Sn}-3.0 \mathrm{Ag}-0.5 \mathrm{Cu}$ solder paste with different type of no-clean flux, namely Flux A and Flux B was evaluated. Besides, its effect towards multiple reflow was also studied. This study also aims at investigating the growth behaviour of IMC at the solder joint as well as the mean thickness of IMC formed at the solder/ $\mathrm{Cu}$ interface.

\section{Experimental Set Up}

The samples were received from Electronic Packaging Research Society-Universiti Kebangsaan Malaysia (EPRS-UKM) where two PCB with immersion tin

\footnotetext{
${ }^{\mathrm{a}}$ Corresponding author: rabiatull@ump.edu.my
} 
(ImSn) surface finish underwent reflow soldering at $240^{\circ} \mathrm{C}$ for 10 minutes. These PCBs were using Sn$3.0 \mathrm{Ag}-0.5 \mathrm{Cu}$ solder paste with different type of noclean flux. Since the exact ingredient of the no-clean flux remain confidential by the Redring Solder Sdn Bhd, they were labelled as Flux A and Flux B. However, it is known that the flux is an epoxy based. Next, the samples proceeded with another reflow process at $250^{\circ} \mathrm{C}$ for 25 minutes in a furnace. This process was done at Universiti Malaysia Pahang (UMP). Figure 1 shows the reflow profiles used in this study. The samples were then undergoing metallography analysis in order to characterise the IMC formation. Several techniques were used to characterize the samples which include optical microscopy, scanning electron microscopy-energy dispersive xray (SEMEDX) and imageJ software.

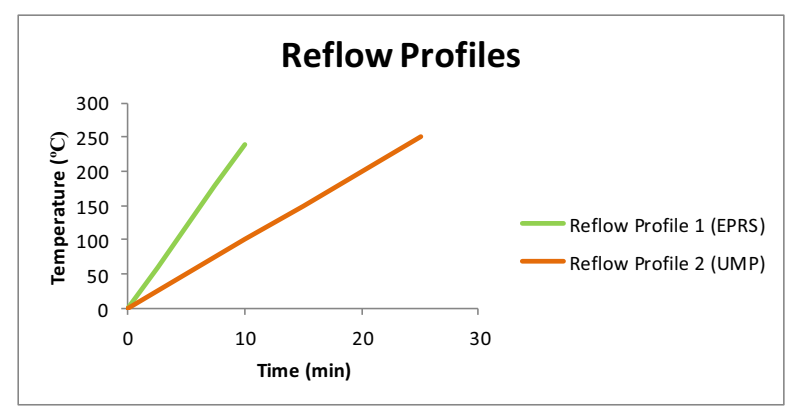

Figure 1. Reflow soldering profiles of printed circuit boards.

\section{Results and Discussion}

According to Table 1, results showed that Flux A had better soldering performance than Flux B. This indicated that $\mathrm{Sn}-3.0 \mathrm{Ag}-0.5 \mathrm{Cu}$ solder paste exhibit better wettability with Flux A on copper substrate. It is known that an optimum wetting angle of the solder joint should be less than $90^{\circ}$. Eventhough the composition of the flux was not mentioned by the supplier, it is believed that chemical composition inside the flux can improve wettability of the activators. These combination decomposed into acid and alkali and reacted with oxides on both substrate and solder surface during reflow soldering. Thus, enhancing the soldering capability.

Table 1. Wetting angles for intermetallic compound using Flux A and Flux B

\begin{tabular}{|c|c|c|}
\hline Flux & $\begin{array}{c}\text { Average } \\
\text { Wetting Angle } \\
(\theta)\end{array}$ & $\begin{array}{c}\text { Cross Sectional view of the } \\
\text { sample }\end{array}$ \\
\hline
\end{tabular}

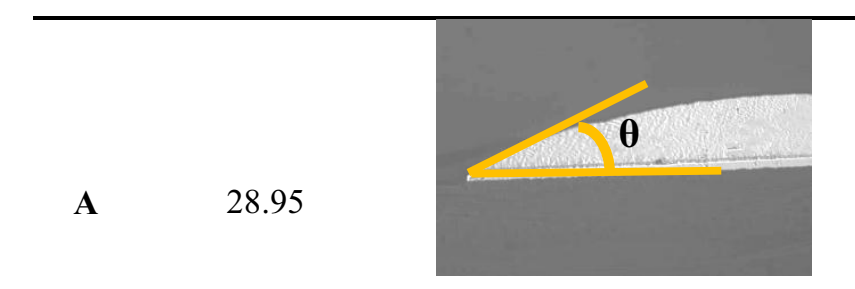

B

41.20
Other than that, in the soldering process, IMC formation can be affected due to many factors which include reflow temperature or profile. The effect of reflow profile for lead solder joint has fully discovered unlike the lead-free solder joint $[12,13]$. In determining the IMC thickness, the reflow peak temperature and time are the critical variables. The liquidus temperature of $\mathrm{Sn}-3.0 \mathrm{Ag}-0.5 \mathrm{Cu}$ are between 217 and $218^{\circ} \mathrm{C}$, which is $34^{\circ} \mathrm{C}$ higher than eutectic $\mathrm{SnPb}$ solder. This is means the liquidus temperatures of lead-free alloys are higher than $\mathrm{SnPb}$ alloy. A thicker IMC layer is expected to form at a higher reflow temperature since the rate of dissolution of the base material in molten alloy is faster as temperature increases. However, higher lead-free solder temperature did not produce thicker IMC layer between the solder and copper substrate of the printed circuit board (PCB). The IMC layer thickness did not change significantly with different reflow profile tested in this study. Nevertheless, it was increasing when exposed to second reflow soldering as shown in Figure 2. In fact, it was found that IMC thickness for Flux A after second reflow higher than Flux B. It is believed that this is due to lower wetting angle produced after first reflow allows the diffusion rate of Sn element from the solder becoming faster. Hence, thicker IMC produced.

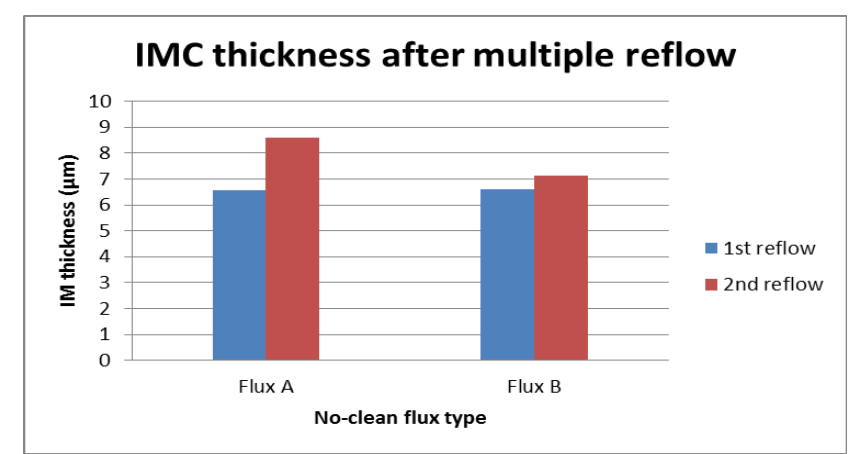

Figure 2. IMC thickness after multiple reflow soldering for both type of no-clean flux.

Moreover, after first reflow only $\mathrm{Cu}_{6} \mathrm{Sn}_{5}$ IMC was detected at solder/Cu interface (Figure $3 \mathrm{a}$ and Figure $3 b$ ). This was proven by energy dispersive xray (EDX) stated in Figure 4a and Figure 4b. While after second reflow, a very thin layer of $\mathrm{Cu}_{3} \mathrm{Sn}$ started to form between $\mathrm{Cu}_{6} \mathrm{Sn}_{5}$ and copper substrate due to lack of Sn element diffused towards copper substrate. It was detected by EDX analysis shown in Figure 4c and Figure $4 d$. In addition, a thin layer of $\mathrm{Cu}_{3} \mathrm{Sn}$ will have no effect on solder joint strength, but if the thickness is equal or more than those produced after isothermal aging, this flux cannot be used for long term usage. 

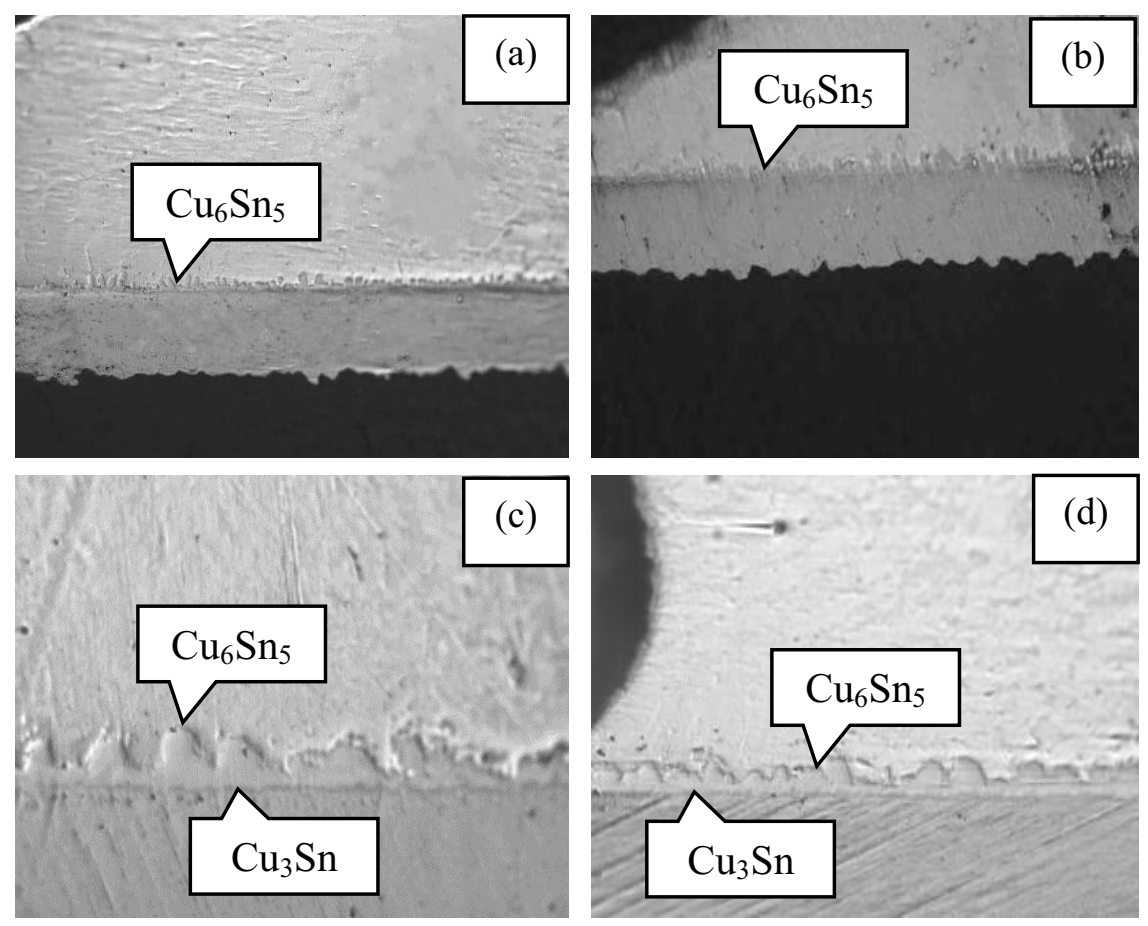

Figure 3. IMC morphology for both type of no-clean flux; (a) first reflow using Flux A, (b) first reflow using Flux B, (c) second reflow using Flux A, and (d) second reflow using Flux B.
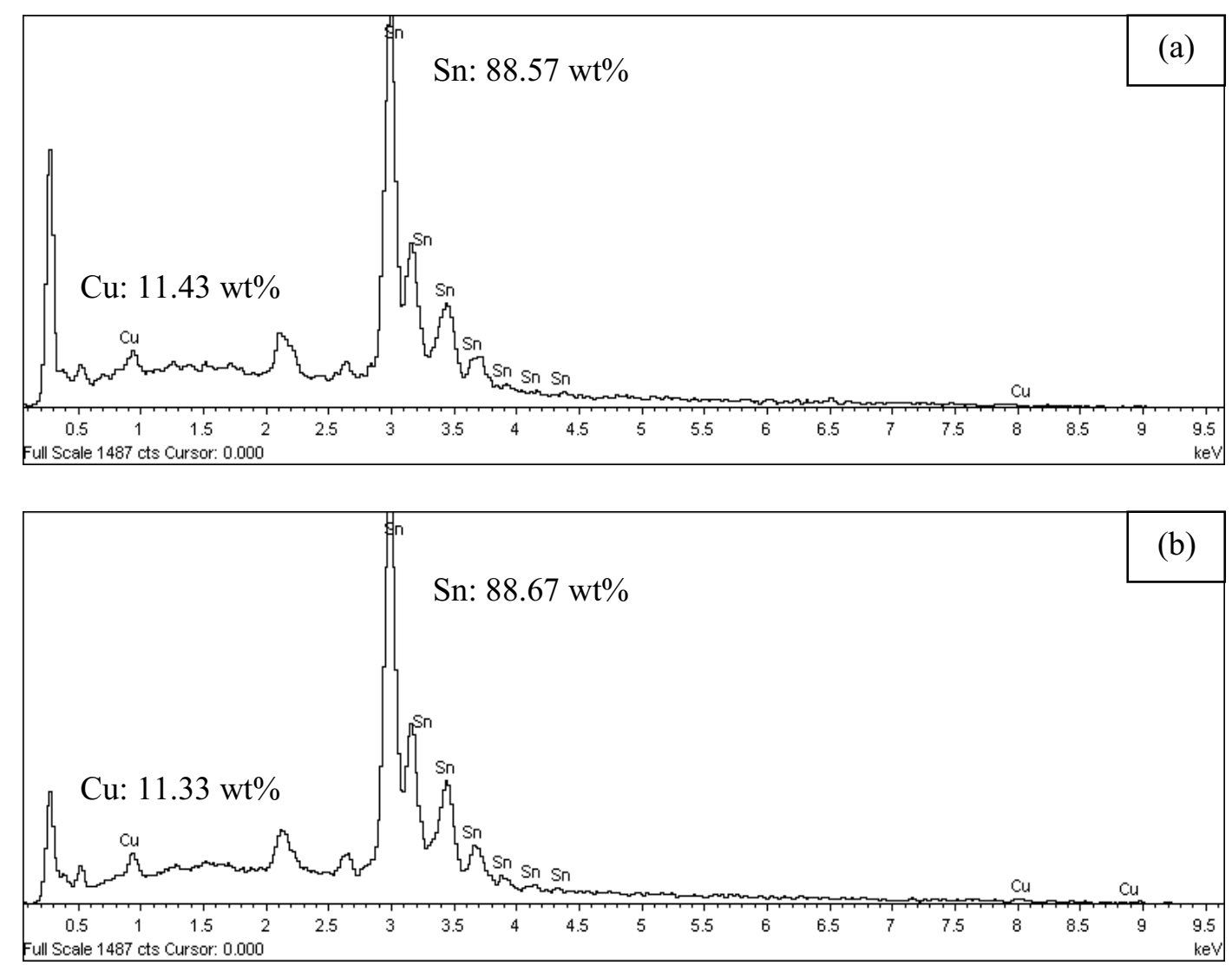

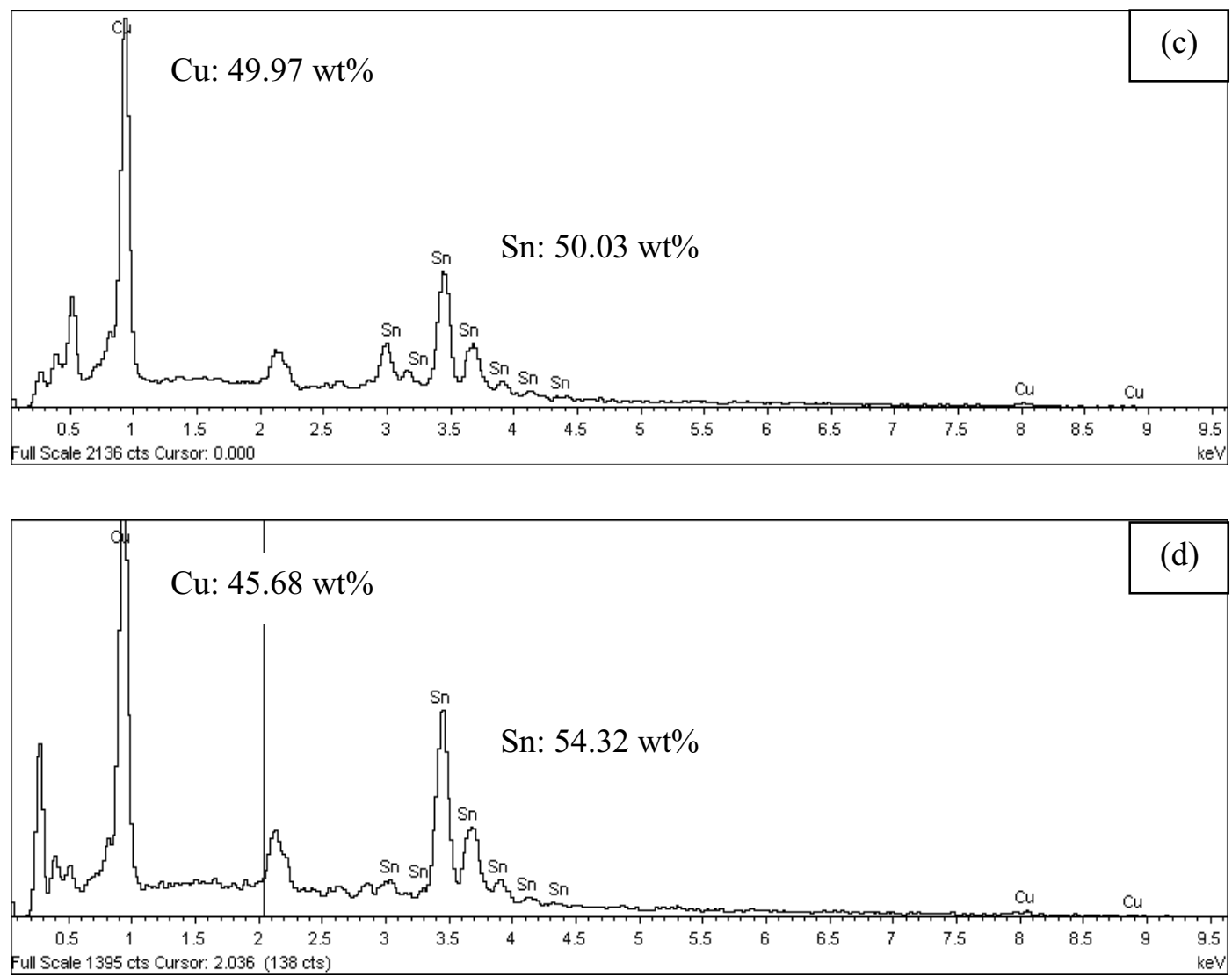

Figure 4. EDX analysis for (a) first reflow using Flux A, (b) first reflow using Flux B, (c) second reflow using Flux A, and (d) second reflow using Flux

\section{Conclusion}

The purpose of the current study was to evaluate wettability of the $\mathrm{Sn}-3.0 \mathrm{Ag}-0.5 \mathrm{Cu}$ solder paste with different type of no-clean flux, namely Flux A and Flux B. Besides, its effect towards multiple reflow was also studied as well as IMC thickness formed at the solder $/ \mathrm{Cu}$ interface was measured. These findings suggest that Flux A is better in terms of soldering performance as compared to Flux B due to the reasons that it manage to produce lower wetting angle as well as suppress IMC thickness after first reflow soldering. However, the solder joint strength need to be evaluated for a further confirmation.

\section{Acknowledgements}

The authors would like to be obliged to Universiti Malaysia Pahang for providing laboratory facilities and financial assistance under project no. RDU130107.

\section{References}

1. X. Dongxia, L. Xusheng, W. Caiqin, and X. Bin. Study on wettability and corrosivity of a new no-clean flux for lead-free solder paste in electronic packaging technology. in Mechanic
Automation and Control Engineering (MACE), 2011 Second International Conference on.(2011)

2. K. Vijay. Miniaturization \&\#x2014; Solder paste attributes for maximizing the print \&amp; reflow manufacturing process window. in Electronic System-Integration Technology Conference (ESTC), 2012 4th.(2012)

3. R. Lathrop. Solder paste printing and stencil design considerations for wafer bumping. in Electronics Manufacturing Technology Symposium, 2004. IEEE/CPMT/SEMI 29th International.(2004)

4. I. Plotog, P. Svasta, T. Cucu, A. Vasile, and A. Marin. Solder paste shelf life extending approach for prototyping and small series activities. in Electronics Technology, 2009. ISSE 2009. 32nd International Spring Seminar on.(2009)

5. W. Schmitt. Resin / Rosin Free Solder Pastes and Fluxes. in Electronics Systemintegration Technology Conference, 2006. 1st.(2006)

6. M. Abtew and G. Selvaduray, Lead-free Solders in Microelectronics. Materials Science and Engineering: R: Reports, 27(5-6): p. 95141.(2000)

7. M. Alajoki, L. Nguyen, and J. Kivilahti. Drop test reliability of wafer level chip scale packages. in Electronic Components and 
Technology Conference, 2005. Proceedings. 55th.(2005)

8. T. Gorewoda, J. Anyszkiewicz, Z. Mzyk, and $Ł$. Buzek, The development of correct methods for $\mathrm{Sn}-\mathrm{Pb}$ solder analysis by wavelength dispersion X-ray fluorescence spectrometry. Spectrochimica Acta Part B: Atomic Spectroscopy, 92(0): p. 29-33.(2014)

9. K.S. Kim, S.H. Huh, and K. Suganuma, Effects of intermetallic compounds on properties of $\mathrm{Sn}-\mathrm{Ag}-\mathrm{Cu}$ lead-free soldered joints. Journal of Alloys and Compounds, 352(1-2): p. 226236.(2003)

10. H. Nishikawa and N. Iwata, Formation and growth of intermetallic compound layers at the interface during laser soldering using $\mathrm{Sn}-\mathrm{Ag}$ $\mathrm{Cu}$ solder on a $\mathrm{Cu} \mathrm{Pad}$. Journal of Materials Processing Technology, 215(0): p. 611.(2015)

11. O. Saliza Azlina, A. Ourdjini, and I. Siti Rabiatull Aisha, Effect of nickel doping on interfacial reaction between lead-free solder and Ni-P substrate. p. 1375-1379(2012)

12. P. Liu, P. Yao, and J. Liu, Effects of multiple reflows on interfacial reaction and shear strength of $\mathrm{SnAgCu}$ and $\mathrm{SnPb}$ solder joints with different $P C B$ surface finishes. Journal of Alloys and Compounds, 470(1-2): p. 188194.(2009)

13. I.S.R. Aisha, A. Ourdjini, M.A. Hanim, and O.S. Azlina, Effect of Reflow Profile on Intermetallic Compound Formation. IOP Conference Series: Materials Science and Engineering, 46(1): p. 012037.(2013) 